\title{
Notes on the vocalizations of Spotted Creeper (Salpornis spilonotus)
}

Peter Boesman

In the following we briefly analyze and compare voice of the different races of Spotted Creeper (Salpornis spilonotus). We also try to quantify the extent of any vocal differences using the criteria proposed by Tobias et al. (2010), as a support for taxonomic review. We have made use of sound recordings available on-line from Xeno Canto (XC).

Comparison of songs:

India
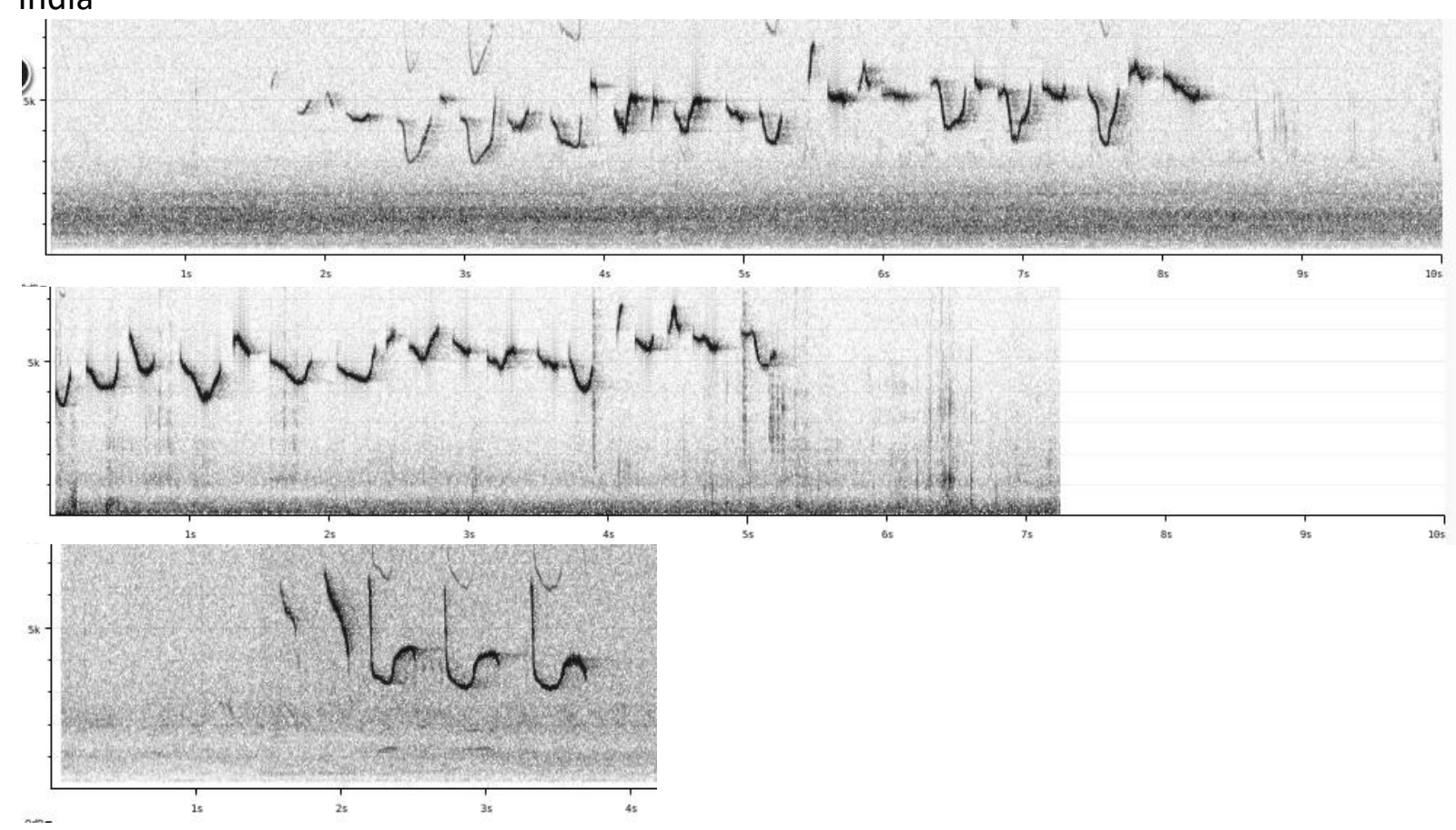

Ethiopia (erlangeri)

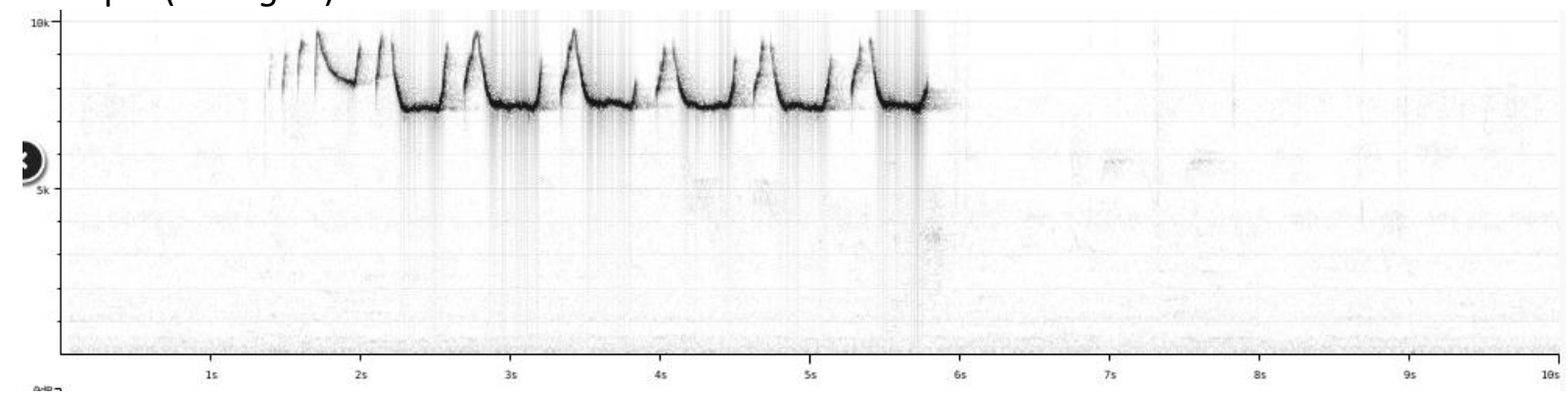


HANDBOOK OF THE

ORNITHOLOGICAL NOTES

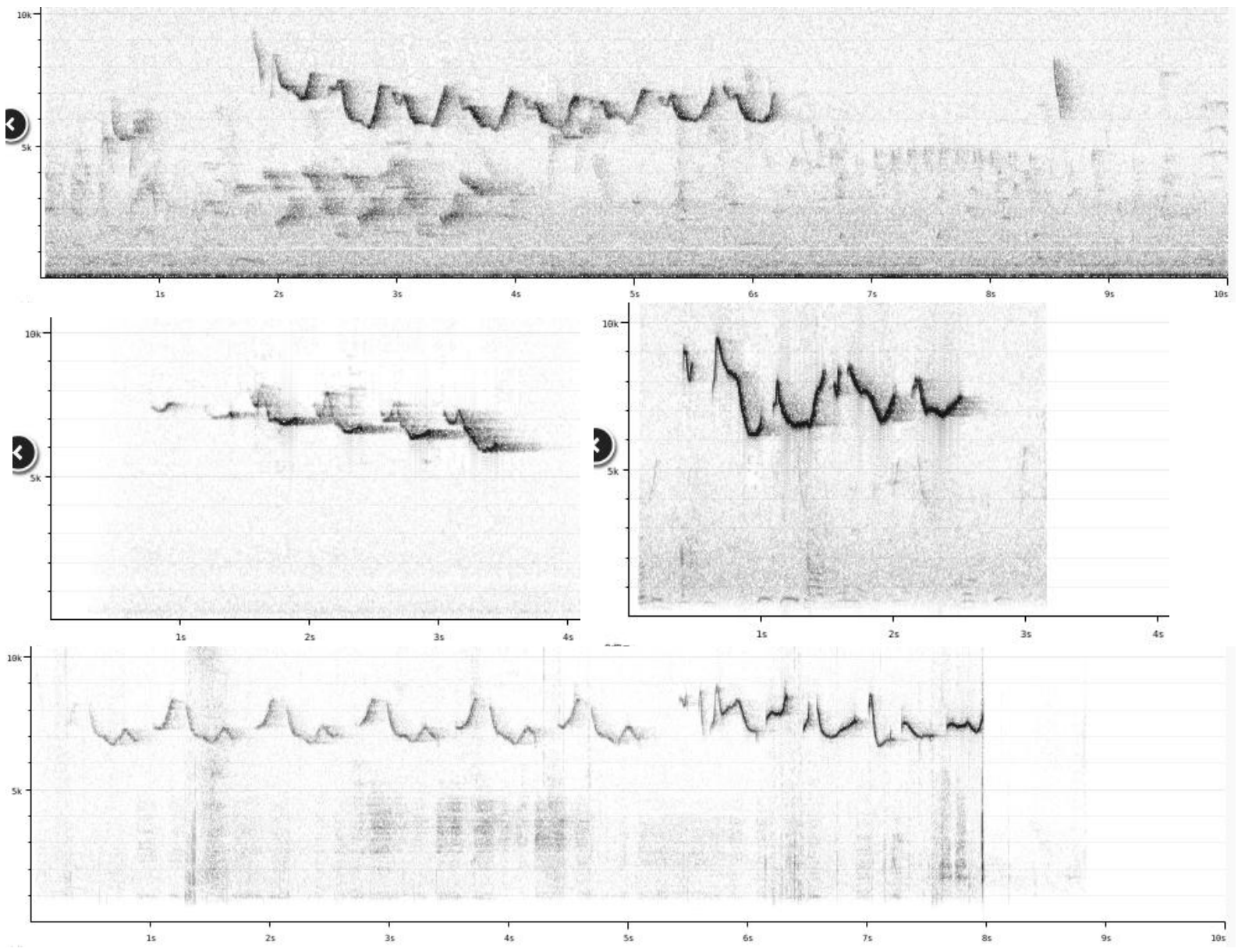

Malawi (salvadori)

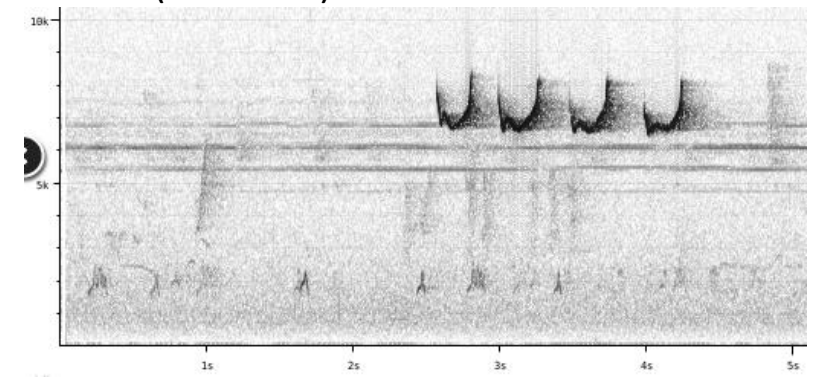

South Africa (?)

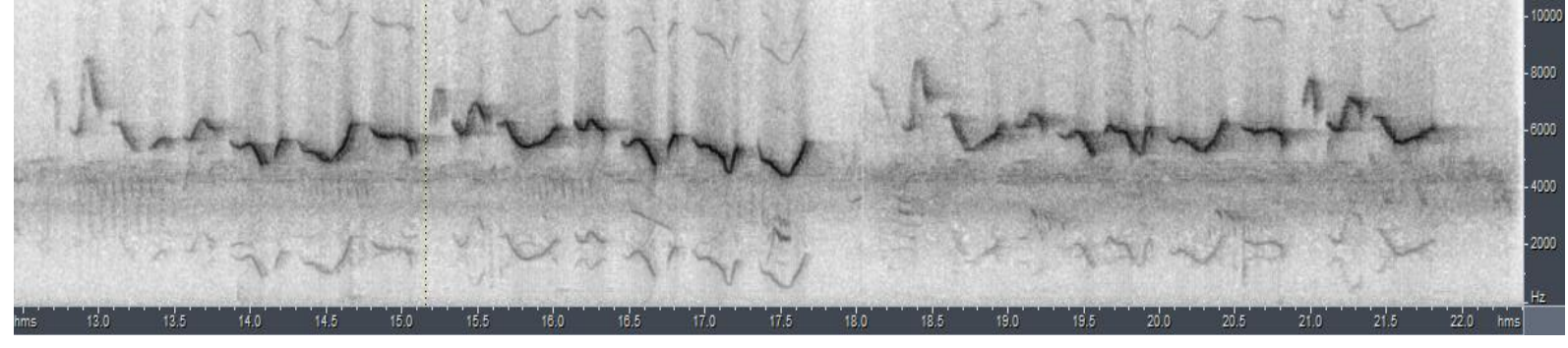



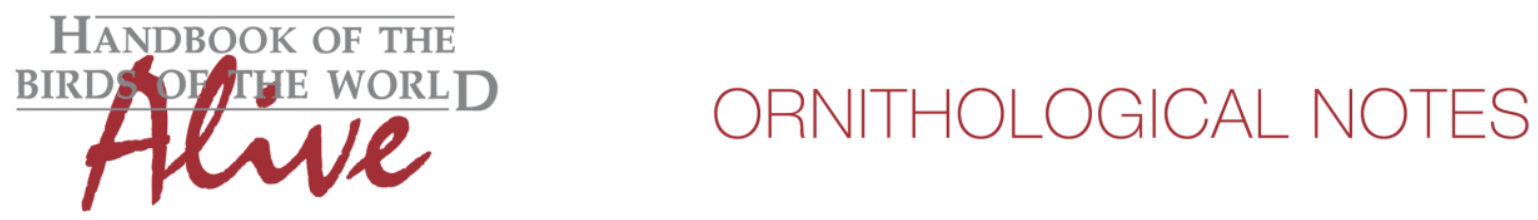

There is quite a bit of variability, and there aren't that many recordings available, but at least one thing is obvious: African birds sing at much higher pitch (min. freq. 5-7kHz, max. freq. 8$9.5 \mathrm{kHz}$ vs. resp. $3-4 \mathrm{kHz}$ and c. $7 \mathrm{kHz}$ ). This would lead to a vocal score of 3.

There seems to be however one exception: race emini from W Africa (no recordings available on-line) also sings at a lower pitch.

Tietze \& Martens (2010) analyzed voice in more detail (Table 5 and Figure 3 of their study here reproduced):

Tab. 5. Means \pm s.d. of several parameters taken from sonagrams of territorial song verses in Salpornis taxa $(n=$ number of males investigated).

\begin{tabular}{|l|c|c|c|c|c|}
\hline Taxon (n) & emini (3) & erlangeri (1) & salvadori (3) & xylodromus (1) & spilonotus (1) \\
\hline Verse length [s] & $1.5 \pm 0.1$ & 2.0 & $3.3 \pm 0.5$ & 2.9 & 3.0 \\
\hline Minimmm frequency [kHz] & $2.6 \pm 0.2$ & 5.3 & $5.7 \pm 0.7$ & 5.0 & 4.1 \\
\hline Maximmm frequency [kHz] & $6.3 \pm 0.3$ & 8.8 & $8.4 \pm 0.5$ & 7.9 & 7.1 \\
\hline Frequency range [kHz] & $3.7 \pm 0.4$ & 3.4 & $2.7 \pm 0.4$ & 2.9 & 3.0 \\
\hline Mean frequency [kHz] & $4.5 \pm 0.2$ & 7.1 & $7.0 \pm 0.5$ & 6.5 & 5.6 \\
\hline Elements & $4.0 \pm 0.6$ & 5.6 & $9.8 \pm 1.5$ & 9.6 & 10.4 \\
\hline
\end{tabular}

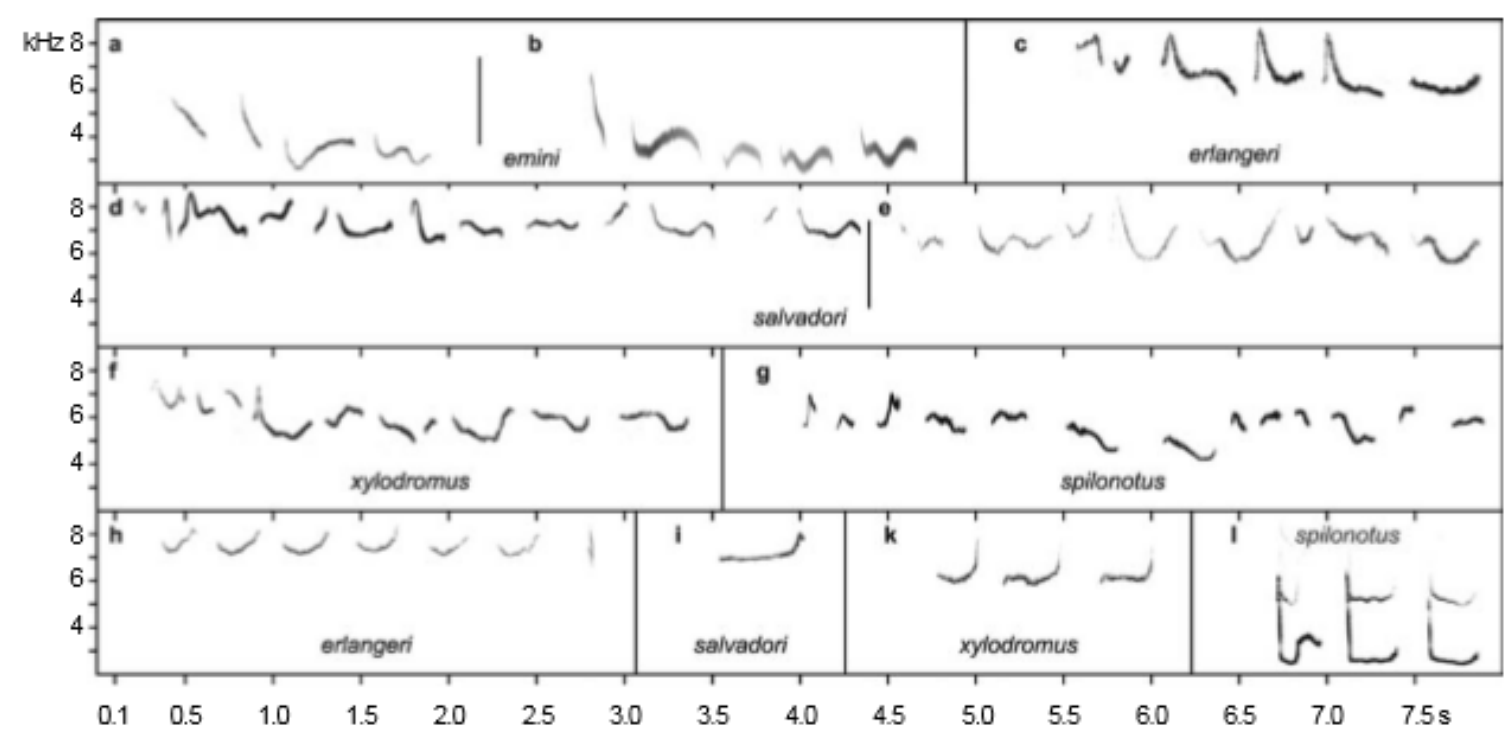

Fig. 3. Sonagrams of territorial songs and calls in Salpornis spilonotus: Song of ssp. emini from a) Côte d'Ivoire (F. Rheindt) and b) Benin (C. Chappuis), of c) ssp. erlangeri from Kenya (R. McVicker), of ssp. salvadori from d) Malawi (C. Chappuis) and e) Zambia (C. Carter), f) of ssp. xylodromus from Zimbabwe (A.C. Kemp), and of g) ssp. spilonotus from India (P.I. Holt); calls of $\mathrm{h}$ ) ssp. erlangeri from Kenya (R. McVicker), i) ssp. salvadori from Zambia (R. Stjernstedt), k) ssp. xylodromus from Zimbabwe (A.C. Kemp), and 1) ssp. spilonotus from India (P.I. Holt).

These measurements confirm that the group erlangeri/salvadori/xylodromus indeed sings at higher frequency compared to spilonotus.

If the few recordings of emini are representative, then it would seem that vocal difference of this taxon with Indian spilonotus is rather the much shorter song phrase (score 2-3), with much less notes (2-3) and lower average frequency (1).

Calls also show differences between African/Indian populations, but there aren't any recordings of West-African race emini (Tietze \& Martens 2010). Vocal differences are similar as in songs: spilonotus has much lower-pitched calls. 

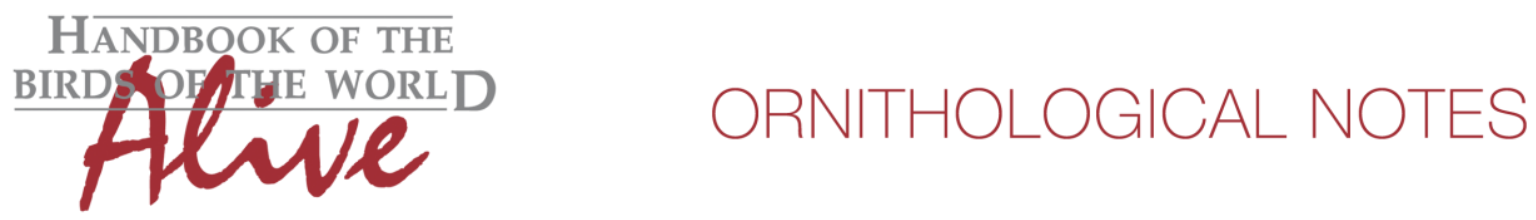

Besides the striking difference in voice between emini and the other African races, it is intriguing that also in morphometrics it is standing somewhat apart. This suggests quite some divergence between these two African groups.

We can thus conclude that:

- Song and call of the Indian group is much lower-pitched than the East-African group (3) as confirmed by multiple recordings, while its song is longer in duration (2-3), having more notes (2-3) and slightly higher frequency (1) compared to West-African group (emini).

- Both African groups differ in similar ways.

This note was finalized on 18th August 2016, using sound recordings available on-line at that moment. We would like to thank in particular the sound recordists who placed their recordings for this species on XC and ML: Rolf de By, Vir Joshi, Guido Keijl, Frank Lambert, David Marques, Jelmer Poelstra, Andrew Spencer

\section{References}

Tietze, D.T. \& Martens, J. (2010). Intraspecific differentiation in Spotted Creepers, Salpornis spilonotus (Aves: Passeriformes: Certhiidae). Vert. Zool. 60(2): 163-170.

Tobias, J.A., Seddon, N., Spottiswoode, C.N., Pilgrim, J.D., Fishpool, L.D.C. \& Collar, N.J. (2010). Quantitative criteria for species delimitation. Ibis 152(4): 724-746.

\section{Recommended citation}

Boesman, P. (2016). Notes on the vocalizations of Spotted Creeper (Salpornis spilonotus). HBW Alive Ornithological Note 279. In: Handbook of the Birds of the World Alive. Lynx Edicions, Barcelona. (retrieved from http://www.hbw.com/node/1251720 on 11 October 2016). 